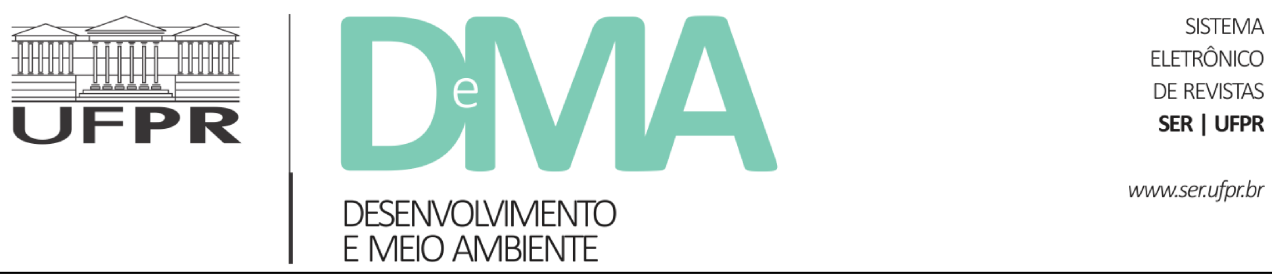

\title{
Los Saberes tradicionales y los desafíos para el Diálogo de conocimientos
}

\section{Os saberes tradicionais e os desafios para o diálogo de conhecimentos}

\section{Traditional knowledge and challenges for the knowledges dialogue}

\author{
Arturo ARGUETA VILLAMAR ${ }^{1 *}$, Maya Lorena PÉREZ RUIZ² \\ ${ }^{1}$ Centro Regional de Investigaciones Multidisciplinarias, Universidad Nacional Autónoma de México (UNAM), Ciudad de México, México. \\ ${ }^{2}$ Dirección de Etnología y Antropología Social, Instituto Nacional de Antropología e Historia (INAH), Ciudad de México, México.
}

*E-mail de contacto: ayruroa@gmail.com

RESUMEN: Los Sistemas de saberes de los pueblos originarios de América Latina o conocimientos tradicionales han sido denominados como: sabiduría popular, saber local, folklore, ciencia indígena (De Gortari, 1963), ciencia de lo concreto (Lévi-Strauss, 1972), ciencia indígena y ciencias nativas (Cardona, 1979), conocimiento popular, ciencia del pueblo (Fals Borda, 1981; 1988); conocimiento campesino (Baraona, 1987; Toledo, 1994) etnoconocimientos, sistemas de saberes indígenas y campesinos (Leff et al., 2002); traditional ecological knowledge (Johnson, 1992), y local and indigenous knowledge systems (LINKS, 2005), entre otras formas. En todos los casos, su nominación ha estado asociada a la interacción asimétrica entre esos saberes con los ámbitos hegemónicos, políticos, jurídicos y académicos que los identifica y categoriza. En la actualidad, esa interacción se desarrolla bajo tensiones múltiples entre las que destacan: 1) El reconocimiento de los pueblos indígenas y sus sistemas de conocimiento en los marcos jurídicos de los Estados nacionales latinoamericanos; 2) El reconocimiento de los saberes tradicionales en instrumentos internacionales y 3) La aceptación, la apropiación o el rechazo de estos sistemas de conocimiento por parte de grupos de investigación de empresas, universidades y centros de investigación. El objetivo de este trabajo es presentar esas tensiones y en ese contexto reflexionar sobre el diálogo de saberes, como una opción posible para generar una interacción de respeto y simetría entre actores con sistemas de conocimiento distintos. Entendiendo el diálogo de saberes, como una praxis reflexiva que pretende construir escenarios respetuosos y no asimétricos para dicha interacción. Estos saberes y prácticas han sido conservados, reproducidos e innovados por los pueblos originarios, afrodescendientes y campesinos de América Latina y el Caribe, a través de múltiples métodos y procedimientos, como lo hemos subrayado en publicaciones previas (Argueta Villamar, 2010; 2011; 2012; 
Pérez Ruiz, 1983; 2018; Pérez Ruiz \& Argueta Villamar, 2011).

Palavras-chave: $\mathrm{CO}_{2}$; PIB; desacoplamento; Kaya; BRICS.

RESUMO: Os sistemas de conhecimento dos povos indígenas da América Latina ou conhecimento tradicional têm sido denominados: sabedoria popular, conhecimento local, folclore, ciência indígena (De Gortari, 1963), ciência do concreto (Lévi-Strauss, 1972), ciência e ciências indígenas. nativos (Cardona, 1979), conhecimento popular, ciência do povo (Fals Borda, 1981; 1988); conhecimento camponês (Toledo, 1994) etno-conhecimento, sistemas de conhecimento indígena e camponês (Leff et al., 2002); traditional ecological knowledge (Johnson, 1992), y local and indigenous knowledge systems (LINKS, 2005), entre outras. Em todos os casos, sua nomeação tem sido associada à interação assimétrica entre esses conhecimentos e as esferas hegemônica, política, jurídica e acadêmica que os identificam e categorizam. Atualmente, essa interação ocorre sob múltiplas tensões, entre as quais estão: 1) O reconhecimento dos povos indígenas e seus sistemas de conhecimento nos marcos legais dos Estados nacionais latino-americanos; 2) O reconhecimento do conhecimento tradicional em instrumentos internacionais e 3) A aceitação, apropriação ou rejeição desses sistemas de conhecimento por grupos de pesquisa de empresas, universidades e centros de pesquisa. O objetivo deste trabalho é apresentar essas tensões e, nesse contexto, refletir sobre o diálogo do conhecimento, como uma opção possível para gerar uma interação de respeito e simetria entre atores com diferentes sistemas de conhecimento. Compreender o diálogo do conhecimento, como uma práxis reflexiva que visa construir cenários respeitosos e não assimétricos para tal interação. Esses saberes e práticas têm sido conservados, reproduzidos e inovados pelos povos indígenas, afrodescendentes e camponeses da América Latina e do Caribe, através de múltiplos métodos e procedimentos, como enfatizamos em publicações anteriores (Argueta Villamar, 2010; 2011; 2012; Pérez Ruiz, 1983; 2018; Pérez Ruiz \& Argueta Villamar, 2011).

Palavras-chave: conhecimento tradicional; lutas indígenas; reconhecimento de direitos; diálogo de conhecimento; América Latina.

ABSTRACT: The systems of knowledge of the indigenous peoples of Latin America or traditional knowledge have been denominated as: popular wisdom, local knowledge, folklore, indigenous science (De Gortari, 1963), science of the concrete (Lévi-Strauss, 1972), indigenous science and sciences natives (Cardona, 1979), popular knowledge, science of the people (Fals Borda, 1981; 1988); peasant knowledge (Toledo, 1994) ethnoknowledge, systems of indigenous and peasant knowledge (Leff et al., 2002); traditional ecological knowledge (Johnson 1992), and local and indigenous knowledge systems (LINKS, 2005), among other ways. In all cases, their nomination has been associated with the asymmetric interaction between these knowledge and the hegemonic, political, legal and academic spheres that identify and categorize them. At present, this interaction takes place under multiple tensions, among which the following stand out: 1) The recognition of indigenous peoples and their knowledge systems in the legal frameworks of the Latin American nation states; 2) The recognition of traditional knowledge in international instruments and 3) The acceptance, appropriation or rejection of these knowledge systems by research groups of companies, universities and research centers. The objective of this work is to present these tensions and in that context reflect on the dialogue of knowledge, as a possible option to generate an interaction of respect and symmetry between actors with different knowledge systems. Understanding the dialogue of knowledge, as a reflective praxis that aims to build respectful and nonasymmetric scenarios for such interaction. These knowledges and practices have been conserved, reproduced and innovated by the indigenous, afro-descendant and peasant peoples of Latin America and the Caribbean, through multiple methods and procedures, as we have emphasized in previous publications (Argueta Villamar, 2010; 2011; 2012; Pérez Ruiz, 1983; 2018; Pérez Ruiz \& Argueta Villamar, 2011). 
Keywords: traditional knowledge; indigenous struggles; recognition of rights; dialogue of knowledge; Latin America.

\section{Consideraciones iniciales}

Educación dialógica, Diálogo intercultural, Encuentro de saberes, Intercambio de conocimientos, Troca de saberes e sementes y Diálogo de conocimientos, son sólo algunos de los términos utilizados desde por lo menos cinco décadas atrás en América Latina, para hacer referencia al encuentro y articulación de conocimientos y prácticas, para hacer posible la solución de problemas contemporáneos, locales, regionales o globales, en el marco de una nueva racionalidad ambiental (Leff, 1994; 2006). Al mismo tiempo que dichas soluciones sean ética, cultural y socialmente pertinentes (Olivé, 2012; 2015), tales como la necesidad de una educación liberadora, revertir la pérdida de biodiversidad, lograr una producción agroecológica para la autosuficiencia alimentaria, mejorar la atención a la salud con procedimientos culturalmente pertinentes en nuestros países pluriculturales y plurinacionales, así como elaborar y establecer nuevas formas y sistemas de convivencia social.

El primero de los conceptos mencionado en la línea inicial, se debe al educador Paulo Freire (1967; 1970), quien, como bien saben los lectores brasileños y latinoamericanos, estableció en la antidialogicidad y la dialogicidad, los ejes analíticos de la alfabetización y la educación liberadora, éste último como diálogo de saberes entre alfabetizador y alfabetizado. El diálogo lo planteó como oposición al monólogo, es decir, como una co-educación dialogada para construir espacios de libertad. Señalamos a este autor y este antecedente fundacional para subrayar la originalidad de esta idea en el ámbito latinoamericano, que da cuenta de la importancia del pensamiento crítico de "Nuestra América", y porque, con cierta frecuencia, cuando abordamos temáticas actuales olvidamos a "nuestros clásicos", haciendo poca justicia a la historia del pensamiento latinoamericano y al pensamiento propio en la construcción de la historia.

Ahora bien, en cuanto al debate contemporáneo sobre el diálogo de saberes, éste se desarrolla en un contexto en donde en ciertos ámbitos científicos predomina aún una concepción nomológico-deductiva de la ciencia, cuyo modelo normativo dominante se sustenta en la física, y desde el cual inclusive se cuestiona el estatuto científico de las ciencias sociales (Giménez, 2009), que son criticadas por su nivel de conceptualización deficiente; por desarrollar una formalización débil y casi inexistente; por presentar múltiples esquemas de inteligibilidad (en lugar de un método único y seguro); por producir resultados poco generalizables; por su imposibilidad de experimentación, por su incapacidad para predecir eventos, y por la no refutabilidad de sus proposiciones (según la argumentación del "modus tollens" de Popper). En ese marco de discusión, es necesario señalar los ámbitos a través de los cuales el debate se está modificando, abriendo espacios a nuevas perspectivas; ya que si bien la filosofía clásica de la ciencia surgió como disciplina en las primeras décadas del siglo XX, y las aportaciones del neopositivismo lógico popperiano fueron arrolladoras en sus inicios, las críticas hechas desde la denominada Nueva filosofía de la ciencia, elaboradas por su fun- 
dador Thomas S. Kuhn, junto a Lakatos, Feyerabend (1982) y otros, dejaron una profunda huella en toda la segunda mitad de ese siglo y derrumbaron buena parte del edificio construido por aquel; $y$ tales autores, junto a Bachelard, Foucault (1988) y Latour, abrieron las puertas al relativismo, al pluralismo epistemológico, al anarquismo metodológico e incluso al relativismo radical.

La explicación kuhniana se separó definitivamente de las concepciones del empirismo lógico y el racionalismo crítico, que entendían a la ciencia recorriendo un camino de acumulación continua, con base en la aplicación de "el método científico", asumido como un método de carácter universal que garantizaba la correcta práctica científica y el conocimiento auténtico, a través de un conjunto de reglas de conocimiento y procedimiento prácticamente infalibles para evaluar hipótesis, teorías, experimentos y resultados. Es por ello que Pérez Ransanz, con base en Kuhn, ha señalado que en algunos análisis sobre el cambio científico todavía se asume implícitamente "que existe un patrón general o dominante de desarrollo, el cual subyace en los diversos cambios de teorías que ocurren en la actividad científica", por lo que otros autores han pensado, sobre todo en las últimas tres décadas, que "una vía más adecuada y profunda sería la de explorar e identificar distintas clases de cambio científico. Distintos tipos de fenómenos diacrónicos, sin cargar el prejuicio de que son, o deben ser- subsumibles en un patrón general" (Pérez Ransanz, 1997, p. 92).
En la grieta abierta por Kuhn entre las corrientes previas (empirismo lógico y racionalismo crítico) y la nueva filosofía de la ciencia, se generó y desarrolló el constructivismo, y se introdujo el pluralismo trayendo consigo nuevas propuestas axiológicas, metodológicas y epistémicas. Olivé señala al constructivismo de Kuhn como la fuente de origen del pluralismo (1999, p. 113). La tesis central del constructivismo afirma que "el contenido del conocimiento y de las teorías científicas está determinado por el marco conceptual o el paradigma que comparten los miembros de una comunidad, el que presuponen en sus prácticas y en sus aproximaciones a la realidad para conocerla y para interactuar con ella, por ejemplo, para transformarla" (Olivé, 1999, p. 115).

Autores como Golinski (al igual que Pickering, 1992, p. 1), establecen la genealogía de las ideas de la sociología del conocimiento científico (SCC) a partir Kuhn, al que señalan como antecedente directo del "Programa fuerte" de la sociología de la ciencia que Barnes y Bloor desarrollaron a mediados de los años setenta, promoviendo el enfoque de que la ciencia debe ser estudiada como otros aspectos de la cultura humana, como un producto social, sin considerar sus supuestos de verdad o falsedad, lo cual fue muy controvertido entre los filósofos e historiadores, pero que tuvo el mérito de inspirar la gestación, a mediados de los años ochenta, del campo que después fue conocido como SCC (Golinski, 1998, p. 5). Por su parte, Olivé señala que después de Kuhn, la obra de Laudan ha contribuido mucho

\footnotetext{
${ }^{1}$ Por su parte Bachelard, primero en El nuevo espíritu científico y sobre todo en La formación del espíritu científico (1987) ya había señalado que los avances en la ciencia no sólo requieren acumulación, sino también ruptura o cortes epistemológicos con los hábitos mentales del pasado. Los avances se producen, dice, venciendo resistencias y prejuicios (a los que llama obstáculos epistemológicos), que son aquellos que pertenecen al cuadro conceptual y a las imágenes dominantes en la configuración epistemológica que ha de superarse. Se trata de nociones similares a las que Kuhn elaborará después y que denominó cambio de paradigma y el tránsito de la ciencia normal a la ciencia revolucionaria.
} 
a cambiar el panorama de la epistemología y de la filosofía de la ciencia en las tres últimas décadas del siglo XX y ha fortalecido el desarrollo de una teoría pluralista de la ciencia. Cabe subrayar dos ideas de Laudan referidas a nuestro tema: "Una adecuada teoría de la ciencia debería permitir un pluralismo metodológico" y "No hay un conjunto fijo de fines de la ciencia, ya que estos fines varían de época en época", con lo que Laudan perfila el pluralismo no sólo en el nivel metodológico sino también en el ámbito axiológico (Laudan, 1986, p. 149).

En el plano del análisis sobre la existencia de diferentes sistemas de conocimiento, el pluralismo sostiene, de manera crucial, la posibilidad de que los sujetos de diferentes culturas interactúen y se interpreten recíprocamente, aunque tengan diferentes concepciones del mundo y estándares de evaluación. Así, se vuelve a poner el énfasis en la interpretabilidad más que en la intertraducibilidad, para superar la inconmensurabilidad, entre marcos conceptuales y visiones del mundo (Kuhn, 1975; Rescher, 1993). En este sentido, se insiste en que el pluralismo "contempla la posibilidad de interacción, incluso interacción dialógica entre miembros de diferentes culturas, mediante esfuerzos de interpretación, y la posibilidad de acuerdos, aunque no necesariamente serán acuerdos completos en todos los asuntos de orden cognitivo o moral. Pero vale la pena observar que los acuerdos completos ni siquiera se dan en el interior de una misma cultura, por más homogénea que ésta sea. Ahora bien, lo que importa es que tanto en el contexto intracultural, como en el transcultural, son posibles los acuerdos sobre cuestiones específicas que interesan a los participantes, y esos acuerdos pueden ser racionales" (Olivé, 1997, p. 51, cursivas nuestras). El pluralismo, concluye Olivé, significa la aceptación de la diversidad en asuntos actuales y en asuntos cognoscitivos, éticos y estéticos; se opone por igual al universalismo y al relativismo extremo y aunque el pluralista no está situado en el punto de vista del ojo de Dios, sino en algún punto terrenal, rechaza también que todas las decisiones y acciones deban juzgarse usando solamente los criterios internos de la cultura de quien actúa. Y si bien el pluralismo aboga por el respeto a otros puntos de vista, no supone la aceptación de que todos los puntos de vista sean igualmente correctos. Por ejemplo, aún cuando insiste en el respeto a todas las culturas, también es cierto que desde los estándares de alguna de ellas en particular, otras culturas no son igualmente valiosas (Olivé, 1997, p. 53). Por ello, anticipa que el pluralismo está marcando un camino por el cual seguirá no sólo la filosofía de la ciencia en el nuevo siglo, sino toda la filosofía, como se ha demostrado recientemente en el terreno de la ética, de la política y de las relaciones interculturales (Olivé, 2000, p. 131).

Todo lo anteriormente expuesto, sumado a las demandas de reconocimiento de los movimientos indígenas, y a la creación de marcos jurídico-legales nacionales e internacionales, como se verá, crearon el ambiente propicio para imaginar nuevas opciones para un diálogo de saberes, en condiciones de respeto y horizontalidad.

Otra consideración más, es que al hablar de conocimientos tradicionales, más que hablar de inmovilidad, la noción da cuenta de los conocimientos que los pueblos consideran propios e imprescindibles para mantener la continuidad de sus culturas e identidades propias. Lo que supone que a lo largo de la historia, éstos han debido transformarse para permanecer. Bajo esta perspectiva los conocimientos indígenas tradicionales serán aquellos que los 
actuales pueblos indígenas consideran propios (Pérez Ruiz 2016), al ser producto de procesos de larga data en que han sufrido transformaciones, producto de la destrucción y la imposición por la acción de agentes externos, pero que también se han enriquecido por la fuerza de la resistencia y por su capacidad de apropiación e innovación de otros conocimientos (Bonfil Batalla, 1987), entre ellos de los científicos. Lo que significa que tales conocimientos no son estáticos ni idénticos a los de la época prehispánica. De forma tal que su evolución debe comprenderse bajo la tensión de la situación colonial (Balandier, 1972) pero también dentro de los parámetros que los pueblos indígenas consideran válidos para seguir considerándolos propios, a pesar de sus transformaciones y de que han adoptado, por imposición o voluntad, elementos de otras culturas y de otros sistemas de conocimiento.

\section{Las batallas de los pueblos por sus identidades, territorios y sistemas de saberes}

Los Estado nacionales en América Latina, se forjaron sobre la base de los modelos monoculturales que se construyeron en Europa y los países anglosajones, por lo que la diversidad cultural y lingüística fue durante sus primeros años de existencia "un gran problema a resolver". Tarea que emprendieron, en unos casos mediante el exterminio de los pueblos originarios, y en otros mediante políticas de incorporación e integración. En respuesta a tales políticas, llevada a cabo por las naciones latinoamericanas, luego de sus procesos de independencia, los pueblos originarios de América Latina, en alianza con otras poblaciones como las afrodescendientes, hicieron del siglo XX un escenario de lucha para la defensa de sus identidades, territorios y sistemas de conocimiento.

Una expresión de estas luchas son las Declaraciones de Barbados y otros documentos (Declaración de Barbados I, 1971; Colombres, 1975; Documentos de la II Reunión de Barbados, 1979; Rodríguez \& Varese, 1981; Bonfil Batalla, 1981). En las fuentes señaladas puede verse que desde principios de los años setenta del siglo XX, tales pueblos comenzaron a establecer organizaciones políticas, de carácter abierto, con diversos niveles de participación y representación, las cuales no sólo generaron demandas sobre problemas ancestrales, para los cuales plantearon propuestas y soluciones originales, sino que abrieron perspectivas para la construcción de una nueva racionalidad social y productiva y una alternativa al paradigma de la civilización occidental y a su modelo insustentable de desarrollo. Desde entonces se plantearon entre sus reivindicaciones las de fortalecer dentro de sus legados culturales y cosmovisiones, los sistemas de saberes indígenas, sus formas simbólicas de percepción, significación y relación con la naturaleza, y sus normas culturales y de organización social para la gestión de un desarrollo propio. Como bien lo señaló Guillermo Bonfil: uno de los mayores 'puntos de ruptura' que permiten ver la diferencia radical entre el proyecto indígena y el proyecto occidental, es su concepción y relación con la naturaleza, donde "el hombre es parte integrante e indisoluble del cosmos y su realización plena consiste en ajustarse armónicamente al orden universal de la naturaleza. El hombre es naturaleza, no domina ni pretende dominar, convive" (Bonfil Batalla, 1981).

Durante la década de los 70 y principios de los 80 , uno de los objetivos básicos de las luchas de los pueblos indígenas estuvo orientado hacia la 
reapropiación de la tierra y la defensa de los recursos naturales, así como la adopción de una educación propia y el derecho al goce de su lengua y cultura. Es por ello que Mejía \& Sarmiento (1987) subrayan que el "movimiento indígena es la expresión de un sector social que no sólo se ha negado a desaparecer a través de los siglos, sino que ahora exige, en virtud de su pertenencia a un grupo étnico, recuperar sus tierras y recursos, recrear su cultura preservando lenguas y costumbres y participar políticamente en la planeación de su futuro."

Es importante constatar a través de la re-lectura de los documentos y resolutivos de los congresos nacionales o de las reuniones supraregionales de los años 70 y 80 , la presencia de demandas y propuestas sobre la lengua, la cultura, la tierra y el ambiente. Son muchos documentos, pero de entre todos ellos son imprescindibles los siguientes: Parlamento Indio Americano del Cono Sur (San Bernardino, Paraguay, 1974), el Primer Congreso de Pueblos Indios de Centroamérica, México y Panamá (Ciudad de Panamá, 1977), la Declaración del Pacto del Valle Matlatzinca (Temoaya, México, 1979), El Consejo Indígena de Sur América y el Primer Congreso de Pueblos Indios de Sur América (Ollaytantambo, Perú, 1980). Y respecto al hemisferio norte del continente americano, el Consejo Mundial de Pueblos Indios (CMPI) coordinado por miembros de las Primeras Naciones de Canadá y de los pueblos indígenas de los EUA, así como de los Saami del Círculo Polar Ártico, emitieron una Declaración de Principios (1975).

El Parlamento Indio Americano del Cono Sur, por ejemplo, realizado en San Bernardino, a orillas del Lago Ypacaraí, Paraguay, en 1974, en el que participaron delegados de Argentina, Bolivia,
Brasil, Venezuela y Paraguay, destaca dos afirmaciones cruciales:

\begin{abstract}
"El indio americano es el dueño de la tierra; la tierra es el indio. El indio es la misma tierra. El indio es el dueño de la tierra, con títulos de propiedad o sin ellos". "Los pueblos indios de América tenemos nuestras propias culturas milenarias" (...). Respetamos la cultura y el idioma de otras civilizaciones, y exigimos que ellas nos respeten con todos nuestros valores, respaldados por la Carta Magna de las Naciones Unidas que señala: 'Cada pueblos tiene derecho a hacer prevalecer su propia cultura'”.
\end{abstract}

De las Conclusiones y recomendaciones del Primer Congreso de Pueblos Indios de Centroamérica, México y Panamá (1977), se elaboraron dos sobre el "extractivismo" que cuarenta años después, sigue uno de los problemas más acuciantes en toda Latinoamérica:

\begin{abstract}
"Por la explotación irracional de los recursos naturales, el presente y el futuro del indio están amenazados [por lo que] Toda explotación minera, fuente hidrográfica, flora, fauna y de otros recursos naturales, en las tierras de los indígenas, sea conocida y aprobada por las autoridades indígenas correspondientes".
\end{abstract}

Convocado por el Consejo Supremo Mazahua y el C. S. Matlatzinca, la reunión efectuada en Temoaya, Estado de México, elaboró una amplia declaración muy importante sobre el tema que nos ocupa:

\footnotetext{
"Reiteramos una vez más el pedido de devolución de nuestras tierras, y el control para nuestras organizaciones de los recursos naturales que existen en las mismas, especialmente las aguas y los bosques. En cuanto a los productos del subsuelo exigimos una participación en los mismos y que se nos consulte y tenga en cuenta nuestra opinión en cuanto a la racionalidad de su explotación". (...). Nos pronunciamos decididamente en contra de la explotación intensiva que realiza el capitalismo de los recursos naturales no renovables y de los
} 
renovables, cuando tal explotación exceda su capacidad de recuperación. No podemos entregar a nuestros hijos menos de lo que tenemos recibido de nuestros padres (...). El irracionalismo cada vez más visible del sistema capitalista occidental parece confirmarnos que la civilización está de nuestro lado... (Declaración del Pacto del Valle Matlatzinca, Temoaya, México, 1979).

Convocado por el Consejo Indígena de Sur América (CISA), se organizó en Cuzco y Ollaytantambo, una gran reunión de los pueblos indígenas de la región en 1980, en donde se plantearon los siguientes considerandos:

- Que el pensamiento cósmico de la vida y del mundo que nos rodea, es la base sustantiva para comprender la Ideología Indianista, la cual significa: orden en constante movimiento y la armónica sucesión de opuestos que se complementan;

- Que la Ideología Indianista como el pensamiento del mismo Indio, de la naturaleza y del universo, es la búsqueda, el reencuentro y la identificación con nuestro glorioso pasado, como base para tomar en nuestras manos la decisión del destino de los pueblos indios;

- Que el Indianismo se nutre en la concepción colectivista y comunitarista de nuestra civilización tawantinsuyana, basada en la filosofía del bienestar social igualitario;

- Que la concepción científica india, define al hombre como parte integrante del cosmos y como factor de equilibrio entre la naturaleza y el universo, ya que de ello depende el desarrollo de su vida creadora en la tierra (Ideología y Filosofía Indianista, Ollantaytambo, 1980).
Mientras tanto, en América del Norte se gestaron otras propuestas que influyeron en las reivindicaciones indígenas de Latinoamérica. La más significativa fue el surgimiento del Consejo Mundial de Pueblos Indios (CMPI) coordinado por miembros de las Primeras Naciones de Canadá y de los pueblos indígenas de los EUA, así como de los Saami del Círculo Polar Ártico, emitieron una Declaración de Principios (1975) que fue presentada ante la Organización de las Naciones Unidas. De los 19 principios que ahí se establecen, cinco de ellos se refieren directamente al ambiente y al territorio:

- Los pueblos indígenas tienen el derecho inalienable a sus tierras tradicionales y al uso de los recursos naturales que les han usurpado sin su consentimiento libre y fundamentado, los que deberán serles devueltos (Principio 10).

- Las tierras a las que tienen derecho los pueblos indígenas comprenden: el suelo, el subsuelo, las aguas territoriales costeras internas y las zonas económicas costeras, todas dentro de los límites fijados por la legislación internacional (11).

- Todos los pueblos indígenas tienen el derecho de usar libremente su riqueza y sus recursos naturales a fin de satisfacer sus necesidades y en conformidad con los principios [anteriores] (12).

- No se llevará a cabo ninguna actividad ni procedimiento que directa y/o indirectamente provoque la destrucción de la tierra, el aire, el agua, los glaciares, la fauna, el medio ambiente o los recursos naturales sin el consentimiento libre y bien fundamentado de los pueblos indígenas afectados (13).

- Los pueblos indígenas y las autoridades que éstos designen tienen derecho a ser consultados y a autorizar la realización de investigaciones 
en ciencia y tecnología en sus territorios y a ser informados sobre los resultados de las mismas (18).

Como puede verse, entre los decenios de 1970 y 1980 se dio un gran salto ideológico, político y organizativo. Mientras en el Parlamento de 1974 se plantearon problemas sobre las condiciones de vida de los pueblos indios, tan solo seis años después, las soluciones a las diversas problemáticas y las perspectivas se plantearon también en términos de liberación y descolonización. Aunque cabe decir que había discrepancias en el sentido que dicha liberación debería tener, según se conceptualizara la finalidad de la lucha: para unos se trataba de una lucha de clases para alcanzar una igualdad económica y redistributiva; y para otros se trataba, ante todo, de la lucha de pueblos que habían sido colonizados y que debían recuperar su capacidad histórica de existir como tales. En este caso la lucha por la liberación debía asumir un perfil específico al enfocarse al reconocimiento de los pueblos originarios que habían sido colonizados, lo que implicaba que éstos fueran reconocidos como constitutivos de los Estados nacionales para que pudieran ejercer sus derechos políticos a la autodeterminación, y poseedores de una perspectiva civilizatoria diferente a la de occidente.

Otro momento cumbre de dichos procesos de autoafirmación, se gestó desde los años previos a la así llamada "Conmemoración del Quinto Centenario del Descubrimiento de América", que desde España se veía como el festejo del descubrimiento y que por ello llamaron también "El Encuentro de Dos Mundos", mientras que para los pueblos originarios significaba la conmemoración luctuosa de la invasión de América.
Así, en 1989, fue lanzada en Bogotá, Colombia, la Campaña Continental 500 Años de Resistencia Indígena, Negra y Popular, misma que culminó el 12 de octubre de 1992. Dicha campaña tuvo como uno de sus objetivos construir la unidad de la diversidad, al convocar a organizaciones y sectores sociales disímbolos que habían mantenido luchas por separado, en un momento en que en toda América Latina se daba el giro de las políticas nacionalistas, y en muchos casos posrevolucionarias, hacia el modelo neoliberal promovido en el mundo, por instancias multilaterales como el Banco Mundial y el Fondo Monetario Internacional. Bajo la cobertura de esa campaña en diversos países se gestaron nuevas organizaciones y movilizaciones que lograron cambiar el carácter de la conmemoración del Quinto Centenario así como para presionar a los Estados nacionales para que reconocieran en sus constituciones los derechos de los pueblos indígenas. Este es un momento cumbre porque en América Latina se expresa una etapa en donde la identidad y la lucha por la autonomía y el reconocimiento de derechos constituyeron el eje central de las movilizaciones, originando lo que para muchos fue el perfil de los movimientos sociales que caracterizaron el final del siglo XX. En este momento cobró relevancia el renombrar la tierra que los europeos llamaron América, y se fortaleció entre el movimiento indígena continental la noción de Abya Yala para nombrar el continente. Es ante todo una categoría política, sin referentes históricos verificables, en cuanto a que pueda referirse en su origen a todo el continente. Literalmente en lengua Kuna significa Tierra en plena madurez o Tierra en florecimiento ${ }^{2}$. 
Para los reclamos de las autonomías indígenas en la década de 1990 existían dos precedentes: por un lado, la existencia desde 1925 de la creación de Comarcas, como la de Kuna Yala homologables al municipio (proceso que abarcaba ya casi el 20\% de la superficie de Panamá) y, por otro, las Regiones Autónomas del Atlántico Norte y del Atlántico Sur de Nicaragua, como entidades territoriales subnacionales de carácter multiétnico con una Cámara Representativa y con cierta capacidad ejecutiva y financiera (Marti i Puig, 2010; CEPAL, 2014). Dos experiencias que, por una parte, ponen en la palestra la discusión de los vínculos posibles entre la lucha de clases y los derechos de los pueblos colonizados $y$, por el otro, permite concentrar en la demanda autonómica un conjunto de derechos sustantivos, como la libertad de optar por un régimen político propio la elección directa de sus autoridades, buscar su propio desarrollo económico, social y cultural, administrar sus recursos, el ejercicio de sus facultades legislativas, reglamentarias, fiscalizadoras y ejecutivas por parte de sus gobiernos autónomos, dentro de sus ámbitos de jurisdicción, así como generar los acuerdos que garantizarán su continuidad como pueblos. Todo lo anterior en el marco de la obligación de los Estados nacionales de negociar con una entidad colectiva poseedora de derechos preexistentes a su creación.

En pleno auge de la reconversión de los Estados nacionales latinoamericanos hacia el neoliberalismo, mediante el eufemismo de adelgazarlos y modernizarlos, en México, en 1994 el Ejercito Zapatista de Liberación Nacional (EZLN) le declara la guerra al gobierno federal mexicano. Se opuso a la entrada en vigor del Tratado de Libre Comercio de las Américas con Estados Unidos y Canadá, y a las reformas constitucionales que pusieron fin a la reforma agraria y que permitían liberalizar el mercado de tierras (reforma al artículo 27 en 1992). En México, el EZLN se alió con las organizaciones del movimiento indígena que desde 1992 luchaban por la autonomía y aglutinó el amplio descontento social causado por el fin de las políticas de justicia social posrevolucionarias y por el perfil neoliberal del nuevo Estado mexicano.

Como consecuencia de tal levantamiento, el debate en México y América Latina se polarizó entre quienes luchaban por lograr reformas dentro de los Estados nacionales para que éstos reconocieran los derechos indígenas (y adquirieran el perfil de ser multiétnicos y pluriculturales), y los que consideraron que eso era insuficiente y pugnaron por una transformación radical de los Estados nacionales, hasta transformarlos en Estados multinacionales. Dichos Estados reconocen la existencia de múltiples nacionalidades, culturas, lenguas, religiones y formas de espiritualidad, y que incorporan a la institucionalidad las formas indígenas de organización y autoridad.

Si bien desde los años 90 comenzaron a surgir algunas organizaciones supranacionales, muy pocas lograron permanecer al paso de los años. Una de ellas, fundamental tanto en la lucha regional como global, y cuyo tema fundamental es la enorme Selva Amazónica, es la Coordinadora de las Organizaciones Indígenas de la Cuenca Amazónica (COICA), que se presenta como "una organización indígena de convergencia internacional (...) cuya preexistencia se enmarca en la defensa de la vida y

${ }^{2}$ Los foros indígenas bajo la cobertura del principio de Abya Yala pueden consultarse en: http://www.cumbrecontinentalindigena.org/docs_guate.php 
de la Amazonia para continuar como semilla en la tierra y conservar los bosques para un planeta vivo que asegure la continuidad de nuestras presentes y futuras generaciones", ha hecho algunos de los planteamientos más avanzados sobre los bosques, el agua y el clima, a partir de los sistemas de saberes de los pueblos originarios de la Amazonía. Agrupa a representantes de diversas y algunas muy antiguas organizaciones indígenas de la cuenca amazónica: CIDOB de Bolivia, COIAB de Brasil, OPIAC de Colombia, COFENIAE de Ecuador, APA de Guyana, FOAG de Guyana Francesa, AIDESEP de Perú, OIS de Surinam y ORPIA de Venezuela.

Recientemente, por ejemplo, hicieron una convocatoria a los participantes de la Cumbre Global de Acción Climática (\#GACS2018) a que se reconozcan los derechos territoriales indígenas como vitales para detener la destrucción de la selva amazónica. La COICA en alianza con otras organizaciones del mundo, tales como: Articulación de los Pueblos Indígenas de Brasil (APIB), la Alianza de Pueblos y Bosques de Mesoamérica (AMPB) y la Alianza de Pueblos Indígenas de Indonesia Archipiélago (AMAN), emitieron la declaración denominada "Principios Rectores para la Colaboración y Asociación entre Gobiernos Subnacionales, Pueblos Indígenas y Comunidades Locales", dirigida especialmente a mover las decisiones de la Fuerza de Tarea de Gobernadores sobre Cambio Climático y Bosques en la cual subraya: "Estamos aquí para exigir nuestros derechos, proteger nuestro conocimiento tradicional y detener la destrucción de nuestros bosques y la criminalización y asesinato de nuestros pueblos" (...) y "Pedimos al mundo que reconozca nuestra capacidad de proteger los bosques que son fundamentales para prevenir el cambio climático" (San Francisco, California, EUAA, septiembre 2018) ${ }^{3}$.

Lo que las organizaciones indígenas dejan ver en sus demandas, en el siglo XXI, es que si bien durante el siglo XX, han logrado consolidar muchas de sus demandas en torno a la consecución de sus derechos, hoy se enfrentan a la paradoja de contar con el reconocimiento de éstos en legislaciones naciones e internacionales, mientras que, por las reformas estructurales, impulsadas en nuestros países por influencia directa de instancias supranacionales, como el Banco Interamericano de Desarrollo y el Banco Mundial, padecen el creciente y voraz despojo de sus territorios y su patrimonio biocultural.

En 2018, el Foro de los Pueblos Indígenas, en el marco de la VIII Cumbre de las Américas ${ }^{4}$, celebrado en Lima el 10 de Abril, sintetiza muy bien el punto en que se encuentra la lucha de los pueblos indígenas al dedicarse abiertamente a la defensa de sus territorios y a exigir el cumplimiento de la libre determinación de los pueblos indígenas. En él se denuncia "el modelo de desarrollo depredador y destructor donde las corporaciones buscan acumular riquezas para unos pocos, vulnerando nuestros derechos y destruyendo la Madre Tierra, a través de la imposición de mega proyectos extractivos como: la minería, hidroeléctricas, hidrocarburos, forestales, monocultivos y de infraestructura en nombre del desarrollo, que se ejecutan sin la consulta ni

\footnotetext{
${ }^{3}$ Todos los documentos mencionados anteriormente pueden ser leídos en revistas como Pueblo Indio, (puebloindio.org) del Consejo Indígena de Sur América (CISA), el periódico Unidad, editado por el Consejo Regional Indígena del Cauca (cric-colombia.org), y desde luego, la mayoría de las organizaciones tienen ya portales y páginas establecidas en la red, como el de la COICA (coica.org.ec.).

${ }^{4} \mathrm{http}$ ://www.forosocialpanamazonico.com/wp-content/uploads/2018.pdf
} 
el consentimiento libre, previo e informado". Y se demanda directamente a los Estados: para que cumplan con las obligaciones internacionales en la materia de derechos indígenas; garanticen la propiedad de sus territorios ancestrales; cesen las políticas de colonización e invasión de sus territorios; implementen procesos de participación, consulta y consentimiento previo, libre e informado antes de adoptar normas, política, programas y medidas susceptibles de afectar a los pueblos indígenas; garanticen medidas efectivas para la participación plena de las mujeres y jóvenes indígenas en la toma de decisiones de política pública que les afecten; implementen política públicas de salud y educación bilingüe intercultural, incorporando en ellas la historia, cosmovisión, filosofía y saberes ancestrales como parte del proceso de descolonización y buen vivir; promuevan la capacitación de los jueces, fiscales y policías para que conozcan, respeten valoren los sistemas jurídicos de los pueblos indígenas; promuevan el derecho a los medios de comunicación indígena, redes comunitarias y el uso y acceso de las tecnologías de comunicación en los idiomas propios; respete el pluralismo jurídico igualitario; y cese la criminalización y estigmatización de autoridades y miembros de pueblos indígenas por ejercer su autoridad, funciones jurisdiccionales y proteger sus territorios y demás derechos.

Las múltiples formas en que cada pueblo y cada comunidad —en el contexto de las reformas estructurales de los Estados nacionales y de la existencia de amplios marcos jurídicos nacionales e internacionales que reconocen los derechos indígenas-, defienden sus recursos frente a la incursión de las empresas gubernamentales o privadas, nacionales y transnacionales que pretenden despojarlas, constituye el escenario actual de la lucha indígena del continente Americano. Tales luchas están forjando una nueva etapa en la confrontación de los pueblos indígenas contra los Estados Nacionales, sean éstos pluriculturales y multiétnicos o plurinacionales e interculturales. Se trata de una etapa en donde su persistencia como pueblos está estrechamente relacionada con la conservación de sus territorios; con la conservación de los recursos medioambientales y su diversidad; así como con la necesaria descolonización estructural, que los mantiene sujetos a legislaciones nacionales e internacionales que si bien configuran un marco de derechos, no siempre son implementados e incluso en ocasiones no los favorece.

\section{Las políticas de reconocimiento en organismos multilaterales}

En respuesta a los pronunciamiento y acciones que, desde principios de los años setenta del siglo pasado, emitieron un gran conjunto de organizaciones indígenas, desde los organismos multilaterales se emitieron convenios, acuerdos y declaraciones sobre los temas planteados. Así, el ordenamiento internacional ha tenido tres fases: La primera, se desarrolló entre los años 1970 y 1980, cuando el tema de los derechos indígenas se introdujo en la agenda internacional. La segunda fase, llevada a cabo entre 1980 y 1990, cuando redes de organizaciones con diversos actores permitieron generar legislaciones internacionales. Y la tercera etapa, vigente hasta hoy, que demanda el cumplimiento en cada Estado de los tratados internacionales así como el diseño e implementación de políticas específicas para cumplirlas (Marti i Puig, 2004).

En ese marco, pueden entenderse los documentos que han sido elaborados para el reconoci- 
miento de los conocimientos tradicionales, que a continuación mencionamos. Ha sido muy claro, en ese sentido, el pronunciamiento elaborado por la Organización Mundial de la Salud (OMS), respecto a la Medicina tradicinal, en el marco de su Programa mundial sobre la Atención Primaria de la Salud (Ver OMS, 1978; Argueta Villamar, 2012). O también en el caso de la Organización Internacional del Trabajo respecto a los derechos de los pueblos indígenas y tribales (Vease OIT, 1989; López Bárcena, 1996), la elaboración del Convenio sobre la Diversidad Biológica (CDB, 1992) e incluso, la Declaración sobre la ciencia y el uso del saber científico (1999), para abordar el gran tema de los Sistemas de saberes de los pueblos originarios. Dicho documento fue elaborado por el Consejo Internacional para la Ciencia (CIC o ISC por sus siglas en inglés), antes denominado Consejo Internacional de Uniones Científicas (ó ICSU, por ídem), fundado hacia 1931, la más amplia organización científica internacional, no gubernamental, la cual emitió la declaración mencionada durante la Conferencia Mundial sobre la Ciencia organizada por la UNESCO, en la cual recomendó considerar a:

\begin{abstract}
"Los sistemas tradicionales y locales de conocimiento, como expresiones dinámicas de la percepción y la comprensión del mundo, ya que pueden aportar, y lo han hecho en el curso de la historia, una valiosa contribución a la ciencia y la tecnología, siendo necesario preservar, proteger, investigar y promover ese patrimonio cultural y ese saber" (Consideración 26 de la Declaración).
\end{abstract}

La Declaración de Budapest (1999) como también se conoce a este documento, hace un llamado a la acción en diversos ámbitos, por ejemplo: "Desarrollar aún más los marcos jurídicos nacionales para satisfacer las exigencias específicas de los países en desarrollo, tener en cuenta el saber, las fuentes y los productos tradicionales, y velar por el reconocimiento fundado de los propietarios consuetudinarios o tradicionales de ese saber".

Al CIC lo integran academias de ciencias nacionales y uniones científicas internacionales, tanto de las ciencias experimentales y básicas, como de las ciencias sociales y humanas. En 2017 formaban parte del mismo: 122 Uniones científicas multidisciplinarias y 31 Uniones científicas disciplinarias, así como 22 Asociaciones científicas, entre otros organismos, todas ellos representan un total de 142 países.

Una de las resonancias de esa declaración puede seguirse en el trabajo realizado por la "Alianza por un Mundo Responsable, Plural y Unido" que la hizo suya y ha proseguido el debate. La Alianza, es una de las entidades promotoras del Foro Social Mundial y ha invitado a los interesados a reflexionar sobre el tema del Control Social de la Ciencia, con base en grandes temas como la relación entre Ciencia y Saberes, para lo cual se hacen tres preguntas a) ¿Es la ciencia la única vía hacia el conocimiento?, b) ¿Es el conocimiento científico una aproximación, entre otras, a la realidad, o sus cualidades son tales que trasciende las limitaciones históricas y geográficas? y, c) ¿Es posible validar otros conocimientos científicos con recursos del análisis científico? Los otros tres temas son: Desarrollo y sustentabilidad, Democratización de la ciencia y Ciencia y Conciencia, o cláusula de la Ciencia.

Otra de los resultados de la Conferencia Mundial sobre la Ciencia (1999) fue la creación del proyecto internacional denominado Local and Indigenous Knowledge Systems in a Global Society (LINKS) de la UNESCO y el establecimiento de un Grupo de Estudio sobre el tema en el ICSU, formado principalmente por científicos sociales, etnobotáni$\cos$, historiadores y filósofos de la ciencia. 
Al celebrarse los 10 años de la Cumbre de Río, el ICSU refrendó la importancia del tema en un documento más reciente titulado Ciencia, conocimiento tradicional y desarrollo sustentable, presentado en la Cumbre de Johannesburgo, en 2002, en el que se precisa lo que se entiende por conocimiento tradicional, se establece una demarcación entre ciencia y seudociencia, entre seudociencia y conocimiento tradicional, y se proponen diversas líneas de interacción entre ciencia y conocimiento tradicional.

La demarcación de ciencia y seudociencia se establece a través de dos perspectivas, una de corte sociológico y otra de carácter epistemológico. La primera se constata mediante la observación de que un campo seudocientífico está siempre en competencia explícita con una ciencia correspondiente, por ejemplo el creacionismo y el "diseño inteligente" frente al evolucionismo. Se señala también que las propuestas de la seudociencia normalmente no son hechas por personas con educación en el campo científico con el cual están compitiendo, por ejemplo, en el caso aludido, no se trata de biólogos profesionales sino de personas con una base religiosa extra-científica. Respecto a la demarcación epistemológica, la diferencia fundamental puede constatarse en los patrones de desarrollo. Mientras la ciencia intenta aumentar su sistematicidad en todos los aspectos en los que es factible, la seudociencia es principalmente estática y si avanza es sólo en el mejoramiento de su cinturón de protección.

Sobre la demarcación de la seudociencia que hace respecto de los conocimientos tradicionales, señala que éstos han sido desarrollados por pueblos con historias amplias de interacción con el medio ambiente natural, y que se originaron de manera independiente de la ciencia, en un entorno cultural particular y también críticamente, es decir indepen- dientemente de la cultura occidental. Subraya que el conocimiento tradicional no está en competencia con la ciencia, ni la competencia es el resultado necesario de su interacción. Si alguna competencia se plantea entre la ciencia y los conocimientos tradicionales, la iniciativa ha provenido de la gente que quiere que la ciencia sustituya a estas otras formas de conocimiento (ICSU, 2002).

El documento llama a promover el diálogo y a impulsar los procesos de intercambio entre la comunidad científica y los poseedores de los saberes tradicionales. El grupo LINKS apoya trabajos de campo, reuniones de trabajo, elaboración de recomendaciones y publicaciones, y uno de sus reportes del 2006, hace parte de la publicación de conmemoración del 60 aniversario de la UNESCO (Nakashima \& Nilsson, 2006).

Además, el 13 de septiembre de 2007 la Asamblea General de la ONU emite la Declaración de Derechos de los Pueblos Indígenas, la cual establece que los indígenas tienen derecho, como pueblos o como individuos: al disfrute pleno de todos los derechos humanos y las libertades fundamentales reconocidos por las normas internacionales de derechos humanos; que son libres e iguales a todos los demás pueblos y personas por lo que tienen derecho a no ser objeto de ningún tipo de discriminación; que tienen derecho a la libre determinación, por lo cual tienen derecho a la autonomía o al autogobierno en las cuestiones relacionadas con sus asuntos internos y locales, así como a determinar libremente su condición política y a que persiguen libremente su desarrollo económico, social y cultural. Por lo cual tienen derecho a conservar y reforzar sus propias instituciones políticas, jurídicas, económicas, sociales y culturales, manteniendo a la vez su derecho a participar plenamente, si lo desean, en 
la vida política, económica, social y cultural del estado y la sociedad nacional. Además, reconoce derechos culturales y a la identidad, derechos a la salud y al empleo, entre otros ${ }^{5}$. Este conjunto de declaraciones, acuerdos y convenios internacionales, constituyen un marco legal y de compromisos multilaterales que garantizan la participación de los pueblos indígenas, con base en sus Sistemas de saberes indígenas con relación a la salud, sus derechos como pueblos, la conservación y aprovechamiento de la biodiversidad y los ecosistemas, así como el llamdo en todos los casos al diálogo entre las distintas formas de conocimientos que existen en el mundo para resolver los acuciantes problemas que enfrentamos.

Con la Declaración de Derechos de los Pueblos Indígenas (2007) y con la Declaración Americana sobre los Pueblos Indígenas $(2016)^{6} \mathrm{se}$ cierra hasta hoy el régimen internacional a favor de los derechos de los pueblos indígenas. Mismo que dibuja el panorama contradictorio en el que se desarrolla la lucha indígena. Por una parte está ese marco jurídico internacional, que reconoce a los pueblos indígenas como sujetos de derecho y que se suma al marco jurídico de cada Estado Nacional que también reconoce los derechos de los pueblos indígenas. Y por el otro están las reformas estructurales efectuadas por cada uno de estos Estados para consolidar el régimen neoliberal que en los países latinoamericanos ha impulsado su reconversión para que en el siglo XXI sean productores exportadores de materias primas. Con ello han generado en los territorios campesinos e indígenas lo que se ha denominado "Desarrollo del capitalismo extracti- vista", depredador de los recursos bioculturales, en beneficio de capitales transnacionales en colusión con las estructuras gubernamentales y los capitales nacionales. Lo cual ha agudizado las presiones sobre sus territorios y sus recursos bioculturales, así como provocado numerosos conflictos socioambientales.

\section{El reconocimiento en los estados nacionales}

El protagonismo indígena, y el tránsito de la lucha indígena por la educación y la tierra hacia luchas por recuperar sus territorios ancestrales, la autonomía y la libre determinación obligaron a los gobiernos nacionales a poner atención en este actor, aunque no necesariamente para resolver las demandas en los términos en que los movimientos indígenas de cada país lo pretendían.

Es así como, en el marco del reconocimiento de ser Estados pluriculturales y multiétnicos, durante el siglo XX se elevaron a rango constitucional los derechos de los pueblos y/o de las personas indígenas (aunque con variaciones en su alcance), en los siguientes países: Panamá (1972, 1983 y 1994), Nicaragua (1987, 1995 y 2005), Honduras (1982 y 2005), El Salvador (1983 y 2000), Guatemala (1985 y 1998), Brasil (1988 y 2005), Colombia (1991 y 2003), Paraguay (1992), México (1992, 1994 y 2001), Perú (1993 y 2005), Argentina (1994), Costa Rica (1999), Bolivia (1994 y 2004), Ecuador (1994 y 1998) y Venezuela (República Bolivariana de Venezuela, 1999) (CEPAL, 2014). Otros países como Chile, si bien no consideran estos derechos en sus

\footnotetext{
${ }^{5}$ http://www.un.org/esa/socdev/unpfii/documents/DRIPS_es.pdf y https://vimeo.com/9735513

${ }^{6}$ https://www.un.org/esa/socdev/unpfii/documents/DRIPS_es.pdf y https://www.oas.org/es/sadye/documentos/res-2888-16-es.pdf
} 
ordenamientos constitucionales, sí lo han hecho en alguna parte de su legislación (1993). Es decir que entre 1990 y el 2005 en América Latina únicamente Chile y Uruguay no reformaron sus constituciones (Martínez, 2015).

En el marco de la transformación de los Estados hacia el ser multinacionales, lo hicieron Bolivia y el Ecuador.

En Ecuador los planteamientos en torno a impulsar un Estado plurinacional se gestaron en el seno de la Confederación de Nacionalidades Indígenas del Ecuador (CONAIE) desde 1993; en el Movimiento de Unidad Plurinacional Pachakutik-Nuevo País (iniciado en 1995), y continuaron durante la Asamblea Constituyente de 1998, luego de importantes luchas sociales, lograron que se reconociera el carácter pluricultural y multiétnico del Estado ecuatoriano. Con ello se reconocieron por primera vez los derechos colectivos para los pueblos y las nacionalidades indígenas dentro de su territorio. Posteriormente, en 2008, se transitó del Estado pluricultural y multiétnico al configurar un Estado plurinacional e intercultural.

En Bolivia, cuyo nombre cambió al de Estado Plurinacional de Bolivia, también como culminación de las luchas indígenas en convergencia con otros sectores progresistas, se reformó la Constitución en 2009. El artículo primero dice: "Bolivia se constituye en un Estado Unitario Social de Derecho Plurinacional Comunitario, libre, independiente, soberano, democrático, intercultural, descentralizado y con autonomías. Bolivia se funda en la pluralidad y el pluralismo político, económico, jurídico, cultural y lingüístico, dentro del proceso integrador del país". Este principio permitió incluir una circunscripción especial; equiparar el derecho consuetudinario con el ordinario; la creación de un
Tribunal Constitucional Plurinacional donde están presentes los dos sistemas; la consagración de la autonomía indígena a través de instituciones y entidades territoriales para los 36 pueblos originarios; y el control de los recursos forestales en manos de las comunidades indígenas (Marti i Puig, 2010).

En el tema que nos ocupa, cabe decir, que en todas las modificaciones constitucionales se han establecido clausulas sobre el reconocimiento, protección, fortalecimiento de los sistemas de saberes tradicionales, así como el llamado al diálogo y el intercambio de saberes entre especialistas de uno y otro saber.

Por ejemplo, en la Constitución de México, el artículo 2, dice: "La Nación tiene una composición pluricultural sustentada originalmente en sus pueblos indígenas que son aquellos que descienden de poblaciones que habitaban en el territorio actual del país al iniciarse la colonización y que conservan sus propias instituciones sociales, económica, culturales y políticas, o parte de ellas". En su sección A señala que: "Esta Constitución reconoce y garantiza el derecho de los pueblos y las comunidades indígenas a la libre determinación y, en consecuencia, a la autonomía para": "Preservar y enriquecer sus lenguas, conocimientos y todos los elementos que constituyan su cultura e identidad (Inciso IV)".

En la sección B señala la necesidad de "Garantizar e incrementar los niveles de escolaridad, favoreciendo la educación bilingüe e intercultural, la alfabetización, la conclusión de la educación básica, la capacitación productiva y la educación media superior y superior. Establecer un sistema de becas para los estudiantes indígenas en todos los niveles. Definir y desarrollar programas educativos de contenido regional que reconozcan la herencia cultural de sus pueblos, de acuerdo con las leyes 
de la materia y en consulta con las comunidades indígenas. Impulsar el respeto y conocimiento de las diversas culturas existentes en la nación (Inciso II).

En el caso del Perú, el Congreso de la República emitió la "Ley que establece el régimen de protección de los conocimientos colectivos de los Pueblos Indígenas vinculados a los Recursos Biológicos" (Ley No. 27811, año 2002). En dicha ley, el Título I, artículo 1., titulado: Reconocimiento de derechos, expresa claramente que. "El Estado peruano reconoce el derecho y la facultad de los pueblos y comunidades indígenas de decidir sobre sus conocimientos colectivos".

En el marco de esta ley, se subraya que: "Los conocimientos colectivos forman parte del patrimonio cultural de los pueblos indígenas" (Artículo 11) y que "Por ser parte de su patrimonio cultural, los derechos de los pueblos indígenas sobre sus conocimientos colectivos son inalienables e imprescriptibles" (Artículo 12). Artículos subsiguientes establecen las tres formas de registro de los Conocimientos colectivos: a) Registro Nacional Público de Conocimientos Colectivos de los Pueblos Indígenas, b) Registro Nacional Confidencial de Conocimientos Colectivos de los Pueblos Indígenas, y c) Registros Locales de Conocimientos Colectivos de los Pueblos indígenas, indicando que los dos primeros estarán a cargo del Instituto Nacional de Defensa de la Competencia y de la Protección de la Propiedad Intelectual, INDECOPI (Título VI, Artículo 15).

La nueva Constitución de Ecuador, promulgada en 2008, en el Capítulo cuarto denominado "Derechos de las comunidades, pueblos y nacionalidades", se enmarcan un conjunto de artículos que comienzan por definir que "Las comunidades, pueblos, y nacionalidades indígenas, el pueblo afroecuatoriano, el pueblo montubio y las comu- nas forman parte del Estado ecuatoriano, único e indivisible (Art. 56).

Además de garantizar los derechos colectivos consistentes en: "Conservar la propiedad imprescriptible de sus tierras comunitarias, que serán inalienables, inembargables e indivisibles. Estas tierras estarán exentas del pago de tasas e impuestos". "Mantener la posesión de las tierras y territorios ancestrales y obtener su adjudicación gratuita" y "Participar en el uso, usufructo, administración y conservación de los recursos naturales renovables que se hallen en sus tierras" (Artículo 57, incisos 4,5 y 6 ).

La constitución garantiza también: "Mantener, proteger y desarrollar los conocimientos colectivos; sus ciencias, tecnologías y saberes ancestrales; los recursos genéticos que contienen la diversidad biológica y la agrobiodiversidad; sus medicinas y prácticas de medicina tradicional, con inclusión del derecho a recuperar, promover y proteger los lugares rituales y sagrados, así como plantas, animales, minerales y ecosistemas dentro de sus territorios; y el conocimiento de los recursos y propiedades de la fauna y la flora". Además de que "Se prohíbe toda forma de apropiación sobre sus conocimientos, innovaciones y prácticas" (Artículo 57, inciso 12).

El Preámbulo de la Constitución Política del Estado Plurinacional de Bolivia (2009), abre con varios párrafos fundamentales, uno de ellos dice: "El pueblo boliviano, de composición plural, desde la profundidad de la historia, inspirado en las luchas del pasado, en la sublevación indígena anticolonial, en la independencia, en las luchas populares de liberación, en las marchas indígenas, sociales y sindicales, en las guerras del agua y de octubre, en las luchas por la tierra y territorio, y con la memoria de nuestros mártires, construimos 
un nuevo Estado", y de inmediato en el Capítulo Primero, Artículo 2 reconoce que "Dada la existencia pre colonial de las naciones y pueblos indígena originario campesinos y su dominio ancestral sobre sus territorios, se garantiza su libre determinación en el marco de la unidad del Estado, que consiste en su derecho a la autonomía, al autogobierno, a su cultura, al reconocimiento de sus instituciones y a la consolidación de sus entidades territoriales, conforme a esta Constitución y la ley".

En el Capítulo Cuarto, dedicado a los "Derechos de las naciones y pueblos indígena originario campesinos, se encuentra la caracterización de que "Es nación y pueblo indígena originario campesino toda la colectividad humana que comparta identidad cultural, idioma, tradición histórica, instituciones, territorialidad y cosmovisión, cuya existencia es anterior a la invasión colonial española" (Artículo 30 , Inciso I) y se garantiza el gozo de los siguientes derechos: "A su identidad cultural, creencia religiosa, espiritualidades, prácticas y costumbres, y a su propia cosmovisión. A que la identidad cultural de cada uno de sus miembros, si así lo desea, se inscriba junto a la ciudadanía boliviana en su cédula de identidad, pasaporte u otros documentos de identificación con validez legal. A la libre determinación $\mathrm{y}$ territorialidad. A la titulación colectiva de tierras y territorios. A la protección de sus lugares sagrados" (Incisos 2, 3, 4, 6 y 7).

Respecto al tema de los Sistemas de saberes, la Constitución de Bolivia, dice que los pueblos de Bolivia gozan también del derecho: "A que sus saberes y conocimientos tradicionales, su medicina tradicional, sus idiomas, sus rituales y sus símbolos $\mathrm{y}$ vestimentas sean valorados, respetados y promocionados. A vivir en un medio ambiente sano, con manejo y aprovechamiento adecuado de los ecosistemas. A la propiedad intelectual colectiva de sus saberes, ciencias y conocimientos, así como a su valoración, uso, promoción y desarrollo. A una educación intracultural, intercultural y plurilingüe en todo el sistema educativo. Al sistema de salud universal y gratuito que respete su cosmovisión y prácticas tradicionales" (Incisos 9, 10, 11, 12 y 13).

En ese marco de reconocimiento, es que desarrolla en la actualidad la interacción de actores con sistemas de conocimientos distintos, creando un escenario peculiar en el que, como se verá, se combinan viejas y nuevas tendencias.

\section{La tensión entre subordinación- autonomía e imposición-acuerdo}

En América Latina, a lo largo de más de 500 años, la mayoría de las interacciones entre los conocimientos llamados tradicionales y los hegemónicos, han estado marcados por el conflicto, y por la supremacía de los primeros sobre los segundos.

Desde el periodo colonial hasta hoy que nuestros países son independientes, ha habido cinco formas en que los sectores dominantes se han vinculado con los conocimientos llamados tradicionales. La primera es el asombro. La segunda, es el acoso y la destrucción. La tercera es la expropiación selectiva de elementos del conocimiento indígena. La cuarta, es la tolerancia romántica, que tiende a idealizar las sabidurías tradicionales, eliminando las debilidades y sublimando las fortalezas; y la quinta es la etapa de la duda pluralista, que cuestiona la hipervaloración de la ciencia, y pretende una mayor valoración de los conocimientos indígenas (Argueta Villamar, 1997, Pérez Ruiz \& Argueta Villamar, 2011). En la actualidad, si bien las cinco formas 
mencionadas están presentes, el debate importante, como ha podido advertirse, se encuentra en torno a tres aspectos: en la continua expropiación selectiva de elementos del conocimiento indígena, tanto para el beneficio de la ciencia como para intereses empresariales privados; en el sentido en que debería resolverse la duda pluralista; así como en las condiciones que deberían establecerse para que pudiera darse la síntesis de enriquecimiento mutuo de cada sistema de conocimiento.

En ese contexto, desde nuestra perspectiva, la interacción entre actores con sistemas de conocimiento distintos, y en condiciones de asimetría se desarrolla en tres vertientes: la primera que propone el diálogo para la incorporación de los saberes tradicionales en los sistemas científicos, con lo que se intenta romper las resistencias y se retoma la vieja tendencia colonial de la validación de conocimientos para la expropiación; la segunda en que bajo un mayor reconocimiento de los saberes indígenas, se mantiene la verticalidad en la interacción con éstos, y que predomina aun cuando se habla de diálogo intercultural, para romper fronteras, e "hibridizar" mutuamente los diversos sistemas de conocimiento; y la tercera en la que se considera que lo que debe gestarse es el fortalecimiento y desarrollo de los sistemas de conocimiento indígenas, para que después, y sólo bajo un plano de respeto, horizontalidad e igualdad, se pueda dialogar con el conocimiento científico (Pérez Ruiz \& Argueta Villamar, 2011). En los tres modelos, que hemos denominado: "Perspectiva etnocéntrica y colonizadora", "Perspectiva intercultural integradora" y "Perspectiva intercultural colaborativa y descolonizadora" (Pérez Ruiz, 2016), la tensión entre subordinación-autonomía e imposición-acuerdo, tiene grados y formas distintas.
La primera es etnocéntrica y colonizadora porque se plantea la aniquilación, la negación, la invalidación y hasta la destrucción, abierta o encubierta, de los sistemas de conocimientos no considerados científicos; e incluye para fines propios la expropiación, lo mismo que la secularización, traducción, validación y uso, sólo de aquellos conocimientos, recursos y prácticas que considera útiles. La tensión se inclina hacia la subordinación absoluta del "otro" y la imposición en éste de lo que debe perdurar de sus conocimientos, lo que se debe desechar y lo que, en cambio, el "otro" debe aprender de la ciencia. Negando cualquier posibilidad de que los actores subalternos puedan decidir sobre su futuro, e influir en las formas de interacción entre actores dominantes y subalternos, por lo que no existe posibilidad del diálogo.

La segunda, si bien contempla una perspectiva de mayor reconocimiento hacia el valor de los conocimientos indígenas, predomina la verticalidad en la interacción ya que el científico, el investigador consagrado como tal por las instancias académicas, es quien decide conocer, selecciona lo que importa conocer y mantiene el control sobre la interacción con el "otro". Perdura, además la práctica de traducir, validar y de secularizar aquello producido por los "otros" que debe trasladarse, incorporarse, al conocimiento científico que así se enriquece. El discurso que lo justifica emplea la fórmula de la universalidad y la neutralidad de la ciencia que pretende actuar siempre a favor de toda la humanidad.

Una variante en esta perspectiva estriba en el discurso de la hibridación, que considera que en la interacción ambos actores se enriquecen al intercambiar sus conocimientos, y al incorporar uno del otro aquello que le sirve. Sólo que la hibridación, sucede en espacios generalmente bajo el control 
de los que detentan el poder científico, tecnológico, académico, político y aún económico, que son quienes preparan el escenario para el diálogo intercultural, y los que marcan las pautas sobre lo que se puede y debe hibridizar, y sobre aquello que por su valor cultural puede y debe conservarse de lo indígena. Generalmente los aspectos manejables de la diversidad cultural que no ponen a discusión, ni en peligro, el modelo de sociedad dominante, sus formas de desarrollo, sus relaciones sociales asimétricas, ni sus estructuras reproductoras de la desigualdad social y cultural. Aquí la interacción entre los actores portadores de distintos sistemas de conocimiento sigue siendo vertical, aunque con formas menos violentas y evidentes, además que se vale también de la secularización y la traducción de los conocimientos indígenas, aunque selectivamente. Dejando las partes religiosas y míticas sólo para ciertos ámbitos de la vida indígena. El diálogo, cuando lo hay, será posible en la medida en que se hagan equivalencias, traducciones y validaciones, y sus resultados serán híbridos, pero a favor del actor que sustenta el poder y la capacidad institucional para crear, sistematizar y aplicar los nuevos e hibridizados conocimientos creados por esa vía.

La tercera perspectiva, intercultural colaborativa y descolonizadora, contempla, como se enuncia en su nombre, un diálogo entre sistemas de conocimiento autónomos, para que cada actor implicado en el diálogo, participe desde su propia epistemología, en espacios establecidos y acordados para la interacción. Es decir que contempla la interacción de actores con sistemas de conocimiento distintos, cada uno con su epistemología propia, que de forma conjunta acuerden los espacios y las finalidades para la interacción. Aquí, se busca sustituir la verticalidad por el acuerdo sobre las formas y los fines de la interacción, y alejarse de la imposición de significados y transformaciones mediante la construcción de las condiciones para la interacción, o diálogo, que acaben con la asimetría, tanto en la valoración de los conocimientos como en la posición de los actores en el proceso.

\section{Para avanzar en un diálogo colaborativo $y$ descolonizador}

Para avanzar en nuevas formas de interacción y diálogo, son varios los retos que deben enfrentarse. Uno de ellos es partir de reconocer que cada uno tiene su propia epistemología, sus propios lenguajes y sus propios métodos, por lo que cada uno debe de mantener sus espacios de producción, reproducción, transmisión y desarrollo de conocimientos. Y que lo que debe crearse de manera conjunta es el espacio para el encuentro y la interacción entre ambos sistemas de conocimiento, que ha de suceder desde el respeto, la horizontalidad, el pluralismo epistemológico y las aportaciones de cada sistema de conocimiento. Se trata de crear plataformas que bajo acuerdo establezcan las normas para el diálogo y los fines de la participación. En el caso de la investigación, por ejemplo, se debe avanzar hacia modelos de co-investigación que renueven desde cómo construir los problemas, bajo qué conceptos y significados, hasta la construcción de las soluciones y su puesta en marcha, con claridad sobre los beneficios de sus resultados (Pérez Ruiz \& Argueta Villamar, 2011.

Un segundo reto, es tener cuidando de que los bienes públicos y los recursos de autoría colectiva no se empleen para beneficios privados. En este punto se requiere precisar los marcos jurídicos 
vigentes, nacionales e internacionales, para que protejan con eficacia los derechos de los indígenas sobre sus sistemas de conocimiento, de autoría fundamentalmente colectiva; y para que no sean expropiados bajo el eufemismo de que servirán para beneficiar a toda la humanidad. Tal como sucede ahora cuando se aplican los instrumentos de salvaguarda internacionales sobre patrimonio cultural inmaterial, sin la participación efectiva de quienes lo han creado, y sin que haya instrumentos suficientes para garantizar sus derechos.

Uno tercero reto es reconocer las limitaciones de las políticas e instrumentos de reconocimiento, que reproducen estereotipos que minorizan a los conocimientos tradicionales y que en esa medida, pretenden abierta o indirectamente su incorporación a los sistemas de ciencia y tecnología predominantes. Expropiación de conocimientos que en estos casos, no es evidente, al suponer que su integración es por el "bienestar humano", sin que se reconozca que la sociedad mundial es injusta, desigual y asimétrica. Para la integración, por lo demás, los científicos deban recurrir a la traducción y la validación de los conocimientos tradicionales para que puedan ser procesados mediante las formas de racionalización, cuantificación y sistematización propias del método científico. En los hechos, dichos conocimientos son inferiorizados desde el momento en que deben ser traducidos, subsumidos e integrados a los sistemas de conocimiento científicos y al desarrollo tecnológico para "el bien común" y de "toda la humanidad", sin que se reconozca previamente el derecho que deben conservar los pueblos creadores sobre tales conocimientos, y se regulen las formas de uso y usufructo para que ellos sean los principales beneficiarios. Se trata de una medida de incorporación/integración de los conocimientos indígenas a las políticas globales del desarrollo neoliberal que no discute el carácter expropiatorio de tal incorporación, ni cuestiona las condiciones que perpetúan la subalternidad de quienes produjeron esos conocimientos (Pérez Ruiz, 2016).

Un cuarto reto, es combatir los estereotipos, incluso adoptados por intelectuales y líderes de pueblos indígenas, con los cuales se caracteriza a los conocimientos tradicionales. El más ampliamente difundido, es que éstos son empíricos, producto del sentido común, generados y transmitidos por la repetición, por el ejercicio constante de la práctica y el error, sin que cuenten con métodos de experimentación y sistematización. Otro es que al estar articulados profundamente con aspectos religiosos, simbólicos y emocionales, se considera que son producto de una mentalidad pre-moderna, poco desarrollada y no objetiva. Por lo cual se les atribuye un tipo de racionalidad elemental capaz de expresarse sólo oralmente, mediante una aptitud explicativa muy por debajo de las capacidades del conocimiento científico. Tal caracterización omite reconocer las formas múltiples que los pueblos indígenas han desarrollado para generar y transmitir sus sistemas de conocimiento. Entre las cuales destacan sus formas diversas de lenguaje y de transmisión compleja, contenidas, por ejemplo, en sus lenguas, mitologías, rituales, diseños textiles, símbolos, y memoria colectiva (Pérez Ruiz, 2016).

Un quinto es que frente a una tarea de descolonización, además de re-caracterizar y re-valorar los conocimientos indígenas, se requiere el reposicionamiento epistemológico de los conocimientos indígenas, lo que implica por una parte reconocer la forma en que éstos se caracterizan y se nombran dentro de la cultura propia. Para este punto, se requieren nuevas condiciones que hagan posible 
una interacción, no asimétrica ni subordinada, que redunde, entre otras cosas, en que sean innecesarios los procesos de "traducción" y "validación" de un sistema de conocimiento a otro; y se transite, en cambio, por procesos de co-construcción consensuada de significados, que sucedan bajo acuerdos y principios éticos y de justicia epistemológica y social. Se trata de retomar el camino marcado por de Santos (2007) para quien los procesos de transición/traducción deben implicar complejos procesos epistemológicos -inter-culturales e inter-epistémicos-, y darse sobre una base de "justicia cognitiva" y una ontología múltiple. Proceso, que debe dejar atrás la traducción hecha desde el poder para avanzar hacia la construcción de encuentros, entre actores con sistemas de conocimientos distintos, para elaborar conjuntamente los acuerdos de legibilidad, y con ello construir los significados y sentidos que deben prevalecer en las palabras, en los conceptos, y en todo aquello que se considere pertinente, según las finalidades que se acuerden horizontal y conjuntamente.

Valga la reflexión hasta aquí desarrollada, para impulsar lo que aquí consideramos un diálogo de saberes colaborativo y descolonizador.

\section{Referencias}

Argueta Villamar, A. Epistemología e historia de las etnociencias. Tesis de Maestría en Ciencias, Facultad de Ciencias, UNAM, México, 124 pp. 1997

Argueta Villamar, A. Los sistemas de saberes indígenas y el diálogo intercultural. En: Gómez Salazar, M. (Ed.). Reflexiones sobre la sociedad del conocimiento y la interculturalidad en México. México, UNAM, pp. 25-38, 2010.

Argueta Villamar, A. El diálogo de saberes, una utopía realista. En: Argueta Villamar, A.; Corona-M., E.; Hersch,
P. (Coord.). Saberes locales y diálogo de saberes, México, CRIM, UNAM; Centro INAH-Morelos, Proyecto "Compartiendo saberes (Foncicyt 95255), PP. 495-510, 2011.

Argueta Villamar, A. La medicina tradicional indígena de México: el largo camino para su legalización y reconocimiento. En: Argueta Villamar, A.; Gómez Salazar, M.; Antezana, J. N. (Coords.). Conocimiento tradicional, innovación y reapropiación social. México, Siglo XXI, pp. 209-252, 2012.

Bachelard, G. La formación del espíritu científico. México, Siglo XXI Editores, (1987 [1938]).

Balandier, G. El concepto de situación colonial, México ENAH. 1972.

Baraona, R. Conocimiento campesino y sujeto social campesino. Revista Mexicana de Sociología, 49, 167-190, 1987.

Bonfil Batalla, G. Utopía y revolución. El pensamiento político contemporáneo de los indios en América Latina. México, Nueva Imagen, 1981.

Bonfil Batalla, G. México Profundo. Una civilización negada. SEP/CIESAS, México, 1987.

Cardona, G. R. Categorías cognoscitivas y categorías lingüísticas en huave. En: Signorini, I. et al. Los huaves de San Mateo del Mar. INI, México, 1979.

CDB - Convenio sobre la Diversidad Biológica. 1992.

CEPAL, Los pueblos indigenas en América Latina. Avances en el último decenio y retos pendientes para la garantía de sus derechos, Naciones Unidas En: https://repositorio. cepal.org/bitstream/handle/11362/37050/4/ S1420783_es.pdf, consultado en mayo de 2018, 2014.

CISA. Puebloindio.org (Página del CISA. Consultada en octubre 2018).

CRIC. Página del Cric-colombia.org (Consultada en octubre 2018)

COICA. Página de la Coica.org.ec (Consultada en septiembre 2018)

Colombres, A. (Selección y notas). Por la liberación del indigena. Documentos y testimonios del Proyecto Marandú. Buenos Aires: Ediciones del Sol. 1975. 
Declaración de Barbados I, Por la Liberación del Indígena. Barbados, 1971.

Declaración de Barbados II. En: Bonfil Batalla, G. 1981. Utopía y revolución. El pensamiento político contemporáneo de los indios en América Latina, México, Nueva Imagen, 1979.

Declaración del Pacto del Valle Matlatzinca, Temoaya, México, 1979.

De Gortari, E. La ciencia en la historia de México, Fondo de Cultura Económica, México, 1963.

Fals Borda, O. La Ciencia del Pueblo. En: Investigación Participativa y Praxis Rural. Nuevos conceptos en educación y desarrollo comunal. Editorial Mosca Azul. Lima, Perú, pp. 19-47. 1981.

Fals Borda, O. Ciencia propia y colonialismo intelectual. Los nuevos rumbos. 3a. edición, Carlos Valencia Editores, Bogotá, 1988.

Feyerabend, P. La ciencia en una sociedad libre. México, Siglo XXI editores. 1982.

Foucault, M. Las palabras y las cosas. Una arqueología de las ciencias humanas. Siglo XXI editores. México, 1988.

Freire, P. Educacao como practica do libertade. Río de Janeiro, Paz e Terra. 1967.

Freire, P. Pedagogía del oprimido, Uruguay, Tierra Nueva. 1970.

Giménez, G. Pluralidad y unidad en las ciencias sociales. Instituto de Investigaciones Sociales de la UNAM, 2009. En: http://www.gimenez.com.mx

Golinski, J. Making Natural Knowledge. Constructivism and history of science. Cambridge, Cambridge University Press, 1998.

ICSU-UNESCO. Declaración sobre la ciencia y el uso del saber cientifico, París, 1999. www.oei.es/budapest.htm

ICSU-UNESCO. Ciencia, conocimiento tradicional y desarrollo sustentable, París, 2002.

Johnson, M. Lore. Capturing Traditional Enviromental Knowledge. Dene Cultural Institute. International Development Research Centre. Ottawa, Canadá, 1992.
Kuhn, Th. La estructura de las revoluciones cientificas, México, FCE, 1975.

Laudan, L. El progreso y sus problemas. Hacia una teoría del crecimiento científico. Encuentro, Madrid, 1986.

Leff, E. Ciencias Sociales y Formación Ambiental. CIIH, UNAM y Gedisa, México-España, 1994.

Leff, E. Aventuras de la epistemología ambiental. México, Siglo XXI, 2006.

Leff, E.; Argueta, A.; Boege, E.; Porto Gonzalvez, C. W. Más allá del desarrollo sostenible: La construcción de una racionalidad ambiental para la sustentabilidad. Una visión desde América Latina. En: Leff, E.; Ezcurra, E.; Pisanty, I.; Lankao, P. La transición hacia el desarrollo sustentable. Las perspectivas de América Latina y El Caribe. INE-UAM-SEMARNAP, México, pp. 479-578, 2002.

Lévi-Strauss, C. El pensamiento salvaje, 2a reimpresión, Fondo de Cultura Económica. México, 1972.

LINKS - Local and Indigenous Knowledge Systems, UNESCO, 2005. http://portal.unesco.org

López Bárcena, F. Convenio 169 de la OIT: su validez y problemas de aplicación en nuestro país, México, INI, 1996.

Martínez, M. I. Reconocimiento sin implementación. Un balance de los derechos de los pueblos indígenas de América Latina. Revista Mexicana de Ciencias Políticas y Sociales, 251-278, 2015.

Marti i Puig, S. Después de la 'Década de los pueblos indígenas' qué? El impacto de los movimientos indígenas en las arenas políticas de América Latina. Nueva Sociedad, 227, 68-82, 2010.

Marti i Puig, S. Sobre la emergencia y el impacto de los movimientos indígenas en las arenas políticas de América Latina. Algunas claves interpretativas desde lo local y lo global. En: Marti i Puig, S. et al. Etnicidad, autonomía y gobernabilidad en América Latina, Salamanca, Ediciones Universidad de Salamanca, pp. 367-389, 2004.

Mejía, M. C.; Sarmiento, S. La lucha indigena: un reto a la ortodoxia. México, Siglo Veintiuno, 1987.

México. Constitución Política de los Estados Unidos Mexicanos, México, 2002. 
Nakashima, D.; Nilsson, A. Linking Biological and Cultural Diversity: Local and Indigenous Knowledge Systems (LINKS) project. In: Petitjean, P.; Zharov, V.; Glaser, G.; Richardson, J.; de Padirac, B.; Archibald, G. (Eds.). 60 years of Science at UNESCO 1945-2005, UNESCO, Paris, pp. 385-388, 2006.

Olivé, L. Pluralismo epistemológico: más sobre racionalidad, verdad y consenso. En: Velasco, A. (Comp.). Racionalidad y cambio cientifico. México, PAIDÓS-UNAM, pp. 43-55, 1997.

Olivé, L. Multiculturalismo y pluralismo, Paidós, México, 1999.

Olivé, L. El bien, el mal y la razón. Facetas de la Ciencia y la Tecnología. México, Paidós-UNAM, 2000.

Olivé, L. Sociedades del conocimiento, justas democráticas y plurales en América Latina. Pensamiento y Cultura, 151(6), 5-19, 2012.

Olivé, L. El aprovechamiento social del conocimiento tradicional: un problema transdisciplinario. En: Argueta Villamar, A.; Peimbert, G. (Coords.). La ruptura de las fronteras imaginarias, o de la multi a la transdisciplina. México. UNAM - Siglo XXI, pp. 80-103, 2015.

OIT. Convenio 169 de la OIT sobre Reconocimiento y Protección de los Derechos de los Pueblos Indígenas, 1989.

OMS. Atención Primaria de la Salud y la Medicina tradicional, 1978.

ONU. Declaración de las Naciones Unidas sobre los Derechos de los Pueblos Indigenas, 2007.

Pérez-Ransanz, A. R. Cambio científico e inconmensurabilidad. En: Velasco Gómez, A. (Comp.). Racionalidad y cambio científico. México, Paidós-unam, 1997, pp. 43-55, 1997.

Pérez Ruiz, M. L. Cambios en la Organización social de la Producción en el Ejido de Yaxcabá, Yucatán. Tesis de Licenciatura en Antropología Social, México, ENAH, 1983.

Pérez Ruiz, M. L. La traducción y la hibridación como problemas para una interculturalidad autónoma, colaborativa y descolonizadora. Liminar, XIV(1), 15-29, 2016.

Pérez Ruiz, M. L. La milpa como patrimonio biocultural. En:
Yesenia, E.; Hernández, P. L. (Coords.). Biodiversidad, patrimonio y cocina. Procesos bioculturales alimentación-nutrición, México, INAH, México, INAH, pp. 215-236, 2018.

Pérez Ruiz, M. L.; Argueta Villamar, A. Saberes indígenas y diálogo intercultural. Cultura y Representaciones Sociales, 5(10), 31-56, 2011. http://www.journals.unam.mx/ index.php/crs/article/view/24448

Perú. Ley 27811, que establece el Régimen de protección de los Conocimientos Colectivos de los Pueblos Indígenas vinculados a los recursos biológicos. Lima, 24 de julio de 2002.

Perú. Decreto Supremo 006-3016-MINCULT. Creación de Comisión Multisectorial Permanente para Salvaguarda y revalorización de Conocimientos, Saberes y Prácticas Tradicionales y Ancestrales, 2016.

Pickering, A. (Ed.). Science as Practice and Culture. Chicago, The University of Chicago Press, 1992.

Rescher, N. Pluralism. Oxford, Oxford University Press, 1993.

Rodríguez, N.; Varese, S. Experiencias organizativas indígenas en América Latina, México, Dirección General de Educación Indígena (DGEI). Secretaría de Educación Pública (SEP), pp. 133-141, 1981.

Santos, B. S. La reinvención del Estado y el Estado plurinacional, CENDA, CEJIS, CEDIB, Cochabamba, Bolivia. Touraine, A. 1995, "Qué es una sociedad multicultural? Falsos y verdaderos problemas”, en Claves de Razón Práctica, núm. 56, pp.14-25, 2007.

Toledo, V. M. La Apropiación Campesina de la Naturaleza: Un Análisis Etnoecológico. Tesis de doctorado en Ciencias, Facultad de Ciencias, UNAM, México, 1994.

UNESCO. Convención sobre el Patrimonio Cultural. Paris, 2003. 